\title{
Deprivation State Switches the Neurobiological Substrates Mediating Opiate Reward in the Ventral Tegmental Area
}

\author{
Karim Nader and Derek van der Kooy \\ Neurobiology Research Group, Department of Anatomy and Cell Biology, University of Toronto, Toronto, Ontario, \\ Canada M5S 1 A8
}

The population of mesolimbic dopaminergic neurons is believed to be a primary site at which opiates produce their rewarding effects. Using an unbiased, counterbalanced place conditioning paradigm, we reexamined the contribution made by these cells to the rewarding properties of morphine. Rats were conditioned such that distinct environments were paired with an intra-ventral tegmental area (VTA) microinfusion of either $500 \mathrm{ng}$ per $0.5 \mu \mathrm{l}$ per side morphine or $0.5 \mu \mathrm{l}$ per side sterile saline. Furthermore, rats were conditioned either previously drug-naive or while in a motivational state of opiate dependence and withdrawal. We report that pretreatment with the broad-spectrum dopamine antagonist $\alpha$-flupentixol blocked the acquisition of conditioned place preferences for environments paired with morphine microinjections directly into

The mesolimbic dopaminergic pathway originating from the cell bodies in the ventral tegmental area (VTA) and projecting to the nucleus accumbens is considered a fundamental component in the neural system mediating the motivational properties of opiates (Wise and Rompre, 1989; Wise, 1996). Opiate receptors in the VTA are thought to be a primary site at which systemically administered opiates act to produce reward (Britt and Wise, 1983). Indeed, even critics of this model who posit that the mesolimbic pathway is sufficient, but not necessary, for mediating the motivational properties of systemic opiates concur that the rewarding properties of intra-VTA morphine are mediated by this ascending dopaminergic pathway (Koob and Bloom, 1988; Koob, 1992). In contradiction to the hypothesis that morphine's rewarding properties are dopamine-dependent are findings that doubledissociate two separate motivational systems mediating the motivational properties of systemic morphine, systemic heroin, and food (Bechara and van der Kooy, 1992a,b; Bechara et al., 1992; Nader et al., 1994; Nader and van der Kooy, 1996). With respect to opiates, this model posits that dopamine transmission is only important in mediating the motivational effects of opiates when animals are in a deprived state (i.e., opiate-dependent and in withdrawal). The TPP, on the other hand, mediates morphine's rewarding properties only when animals are in a nondeprived state (cases when animals are not in a state of withdrawal: previously drug-naive rats, rats that have recovered from a state of

\footnotetext{
Received July 18, 1996; revised Sept. 11, 1996; accepted Oct. 3, 1996.

This work was supported by a grant from the Medical Research Council of Canada. We thank Dr. Thomas Jaeger for his assistance in preliminary doseresponse studies.

Correspondence should be addressed to Karim Nader, Neurobiology Research Group, Department of Anatomy and Cell Biology, University of Toronto, Toronto, Ontario, Canada M5S 1A8.

Copyright (C) 1996 Society for Neuroscience $0270-6474 / 96 / 170383-08 \$ 05.00 / 0$
}

the VTA in opiate-dependent and withdrawn, but not in previously drug-naive, rats. Lesions of the tegmental pedunculopontine nucleus (TPP) produced exactly the opposite pattern of results. TPP lesions blocked the acquisition of conditioned place preferences for environments paired with VTA morphine microinjections in previously drug-naive, but not in opiatedependent and withdrawn, rats. These data double-dissociate two independent reward substrates within the VTA itself and suggest that deprivation state selects which of these two substrates will be active. Furthermore, these findings are the first to demonstrate a nondopaminergic substrate for reward within the VTA itself.

Key words: $\alpha$-flupentixol; morphine; reward; withdrawal; place preference; tegmental pedunculopontine

dependence, and rats that are opiate-dependent but not in a state of withdrawal) (Bechara and van der Kooy, 1992b; Bechara et al., 1992; Nader et al., 1994; Nader and van der Kooy, 1996). Specifically, the ventromedial portion of the TPP, which contains only a sparse population of cholinergic cells, has been identified as the critical region mediating opiate reward in previously drug-naive rats (Bechara and van der Kooy, 1989). Furthermore, once in a state of deprivation, the TPP-mediated nondeprived system is inhibited (Bechara and van der Kooy, 1992b; Nader and van der Kooy, 1994).

We undertook a rigorous test of whether the mechanisms mediating morphine's motivational properties within the VTA can be best described by actions either through a single dopaminergic mechanism or through multiple dissociable mechanisms that are contingent on an animal's motivational state. Animals were conditioned using an unbiased, counterbalanced place conditioning procedure such that one environment was paired with a just suprathreshold dose (500 ng per $0.5 \mu$ l per side) of morphine bilaterally microinjected directly into the VTA, and the other environment was paired with sterile saline $(0.5 \mu \mathrm{l}$ per side $)$ microinjected into the VTA. We predicted that if the dopaminergic mesolimbic pathway is necessary for mediating morphine's motivational properties, then dopamine antagonists should block the acquisition of conditioned place preferences for environments paired with intra-VTA morphine, regardless of whether animals are trained previously drug-naive or in a state of opiate dependence and withdrawal. On the other hand, if separate systems mediate morphine's rewarding properties, then we predicted that dopamine antagonist pretreatment would block the acquisition of conditioned place preferences for environments paired with intraVTA morphine in opiate-dependent and withdrawn, but not in previously drug-naive, animals. Furthermore, TPP lesions should 
block the acquisition of place preferences for environments paired with intra-VTA morphine in previously drug-naive, but not in opiate-dependent and withdrawn, animals.

\section{MATERIALS AND METHODS}

Subjects. All animals used in these experiments were adult (350-400 gm) male Wistar rats (Charles River). Subjects were individually housed in suspended gray wire cages in a room kept at a temperature of $22^{\circ} \mathrm{C}$ with lights on from 9:00 P.M. to 9:00 A.M. Throughout the duration of the experiments, animals had ad libitum access to food and water.

Surgery. Rats were anesthetized with $0.8 \mathrm{ml} / \mathrm{kg}$ intraperitoneal doses of sodium pentobarbital (Somnitol) and placed in a stereotaxic apparatus with the incisor bar set at -3.3 . All coordinates were taken from Paxinos and Watson (1982). Cannulae were positioned into the VTA using the same procedure as described previously (Jaeger and van der Kooy, 1993). Briefly, 22-gauge guide cannulae were angled $10^{\circ}$ toward the midline and implanted 1.5-2 mm dorsal to the VTA (from bregma: AP -5.0, L \pm 2.3 ; from the dural surface: $\mathrm{V}-8.0)$. The coordinates used for cannulae aimed dorsal to the VTA were AP $-5.0, \mathrm{~L} \pm 2.3$ and from the dural surface $\mathrm{V}-7.0$. The guide cannulae were anchored to the skull by dental acrylic cement and stainless steel screws.

Lesions of the ventromedial TPP were performed by injecting bilaterally $0.2 \mu \mathrm{l}$ of either a $2 \%$ ibotenic acid solution (lesion group) or physiological saline (sham group) via a $1 \mu \mathrm{l}$ Hamilton microsyringe over a $20 \mathrm{~min}$ period. The needle was left in place for $5 \mathrm{~min}$ after the end of the infusion. The injection coordinates for the ventromedial TPP were AP $7.8 \mathrm{~mm}$ posterior to bregma, $\mathrm{L} 1.6 \mathrm{~mm}$ lateral to the midline, and DV $6.8 \mathrm{~mm}$ below the dura. For animals that received both cannulae implantation and TPP lesions, the two surgical procedures were performed at the same time. At least 2 weeks were allowed for recovery from surgery before any conditioning.

Histology. At the end of the behavioral experiments, all rats were deeply anesthetized and intracardially perfused with isotonic saline, followed by $10 \%$ formalin. The brains were removed and post-fixed in a $20 \%$ sucrose solution. The brains were then cut in $32 \mu \mathrm{m}$ sections, which were mounted and stained with cresyl violet to verify the placement of both cannulae and TPP lesions. Sections were examined and photographed under bright-field microscopy.

Microinfusion. For intracranial microinfusions, obturators were removed from the animal's skull cap, and a 28-gauge injector cannula was lowered to the injection site. The injector cannula protruded $1.5-2.0 \mathrm{~mm}$ ventral to the guide cannulae. Polyethylene tubing (PE-50, Clay Adams) connected the injector to a $1 \mu \mathrm{l}$ Hamilton microsyringe, which was loaded with the appropriate solution before microinfusion. The rats were held by the experimenter while infusions were made over a 1 min period. The accuracy of the volume infused was assessed by observing the progress of an air bubble within the tubing. After termination of the infusion, the injector was left in place for an additional $1 \mathrm{~min}$ before being removed.

Apparatus and place conditioning procedure. The place conditioning apparatus was identical to that described previously (Mucha et al., 1982; van der Kooy, 1987). Briefly, conditioning took place in one of two distinct environments that differed in color, smell, and texture. One environment was white with a wire mesh floor that was covered with wood chips. The other environment was black with a smooth Plexiglas floor that was wiped down with a $2 \%$ acetic acid solution before each conditioning session. At testing, a narrow, neutral gray zone (on which the rats were placed at the beginning of each test session) separated the two test compartments.

All animals were conditioned using a standard place conditioning procedure (Mucha et al., 1982; van der Kooy, 1987). With the exception of the preliminary investigations, the conditioning protocol was identical for all experiments. The only independent measures that were manipulated were the state animals were trained in (previously drug-naive vs in a motivational state of opiate dependence and withdrawal) and pretreatment (TPP lesions vs dopamine antagonist). During conditioning, animals were given an intracranial microinfusion of morphine directly into the VTA and exposed to one of the two conditioning environments for 45 min. On the alternate day, rats received microinfusions of sterile saline and were placed in the alternate conditioning environment for the same period of time. This procedure was repeated until each animal had received a total of four drug-environment and four saline-environment pairings. Both treatment compartment and presentation order of drug and vehicle were counterbalanced within groups. Once training was terminated, all rats received a 1 week recovery period during which they were left undisturbed in their home cages. On test day, rats were individually given free access for a $10 \mathrm{~min}$ period to both training environments, and the subsequent times spent in each were recorded. A comparison of the times spent in the drug versus saline paired environments was used as an index for whether animals preferred one compartment over the other.

Animals trained in a state of opiate dependence and withdrawal received daily $0.5 \mathrm{mg} / \mathrm{kg}$ subcutaneous injections of heroin commencing $4 \mathrm{~d}$ before the start of conditioning. During conditioning, this dose of heroin was administered daily $3.25 \mathrm{hr}$ after the termination of training. Although four subcutaneous injections of $0.5 \mathrm{mg} / \mathrm{kg}$ over $4 \mathrm{~d}$ do not induce dramatic classical somatic withdrawal signs, they are sufficient to induce a state of motivational dependence, and $20 \mathrm{hr}$ after heroin injection, the time at which conditioning was performed in the present study, rats are undergoing withdrawal as measured by the conditioned aversions to environments paired with the absence of drug (Nader et al., 1994). The motivational effects of withdrawal induced by this regimen are isomorphic with those observed after a 3 week regimen of morphine administration, which produces aversive motivational withdrawal effects (that are dopamine-mediated) as well as intense somatic withdrawal signs (Bechara et al., 1995).

Preliminary investigations. These studies differed from the above protocol with respect to dose of intra-VTA morphine used to condition place preferences, placement of the injector cannulae, or the training drug. To determine a dose of morphine that produces reliable conditioned place preferences, we performed a dose-response curve for intra-VTA morphine-conditioned place preferences. Separate groups of previously drug-naive animals were conditioned with bilateral intra-VTA morphine $250 \mathrm{ng}$ per $0.5 \mu \mathrm{l}$ per side $(n=8), 500 \mathrm{ng}$ per $0.5 \mu \mathrm{l}$ per side $(n=7)$, or $2500 \mathrm{ng}$ per $0.5 \mu \mathrm{l}$ per side $(n=11)$ injections using the above procedure. On saline days, animals received bilateral $0.5 \mu \mathrm{l}$ per side saline microinfusions into the VTA. Based on the findings from this study, a dose of 500 ng per $0.5 \mu l$ per side morphine was chosen for all subsequent experiments.

We tested whether morphine's rewarding properties were the result of actions within, and not dorsal to, the VTA. One group of previously drug-naive $(n=7)$ and one group of opiate-dependent and withdrawn $(n=6)$ rats were conditioned with 500 ng per $0.5 \mu \mathrm{l}$ per side morphine microinfused $1 \mathrm{~mm}$ dorsal to the VTA. Furthermore, to verify that the mechanisms in the VTA that supported morphine reward were receptormediated, we conditioned another group of previously drug-naive rats $(n=8)$ with $500 \mathrm{ng}$ per $0.5 \mu \mathrm{l}$ per side of the inactive $(+)$-morphine isomer (Jacquet et al., 1977) directly into the VTA.

Effects of $\alpha$-flupentixol on intra-VTA morphine-mediated place preferences. A total of six groups of rats were used for this experiment. Two groups were trained previously drug-naive using a dose of $500 \mathrm{ng}$ per 0.5 $\mu \mathrm{l}$ per side of the active (-)-morphine isomer. Rats were pretreated 2.5 hr before every conditioning session with either $0.8 \mathrm{mg} / \mathrm{kg} \alpha$-flupentixol (i.p.) $(n=7)$ or saline $(n=7)$ injections. At this dose, $\alpha$-flupentixol blocks both D1 and D2 receptors (Creese et al., 1976). Furthermore, at this pretreatment time and dose, $\alpha$-flupentixol does not have any motivational properties itself (Harrington and van der Kooy, 1992). Two other groups of rats were made opiate-dependent and trained in a state of opiate withdrawal using the same $500 \mathrm{ng}$ per $0.5 \mu \mathrm{l}$ per side intra VTA dose of morphine. Again, rats were pretreated $2.5 \mathrm{hr}$ before each conditioning session with either $0.8 \mathrm{mg} / \mathrm{kg} \alpha$-flupentixol (i.p.) $(n=8)$ or saline $(n=9)$ injections.

The last two groups of rats were conditioned previously drug-naive with $500 \mathrm{ng}$ per $0.5 \mu \mathrm{l}$ per side intra VTA morphine. Again, rats received either saline $(n=6)$ or $\alpha$-flupentixol $(n=8)$ injections (i.p.) $2.5 \mathrm{hr}$ before each conditioning session. After testing, these last two groups of animals were counterbalanced between groups with respect to pretreatment $(\alpha-$ flupentixol or saline) and within groups for morphine-paired environments (black or white). That is, half the animals that were in the $\alpha$-flupentixol pretreatment group were now placed in the saline pretreatment group and vice versa. Similarly, half the animals in each group were slotted to receive morphine pairings to the same side as the previous experiment, whereas the other half of the animals in each group were slotted to receive morphine pairings to the side that animals had received saline in the previous experiment. One week after testing for the conditioned place preferences in previously drug-naive animals, these same rats were made dependent (dependence was induced with systemic heroin as described above) and then trained again using the identical protocol as above, but this time while in a state of opiate withdrawal. Rats were pretreated $2.5 \mathrm{hr}$ before conditioning with either $0.8 \mathrm{mg} / \mathrm{kg}$ (i.p.) 


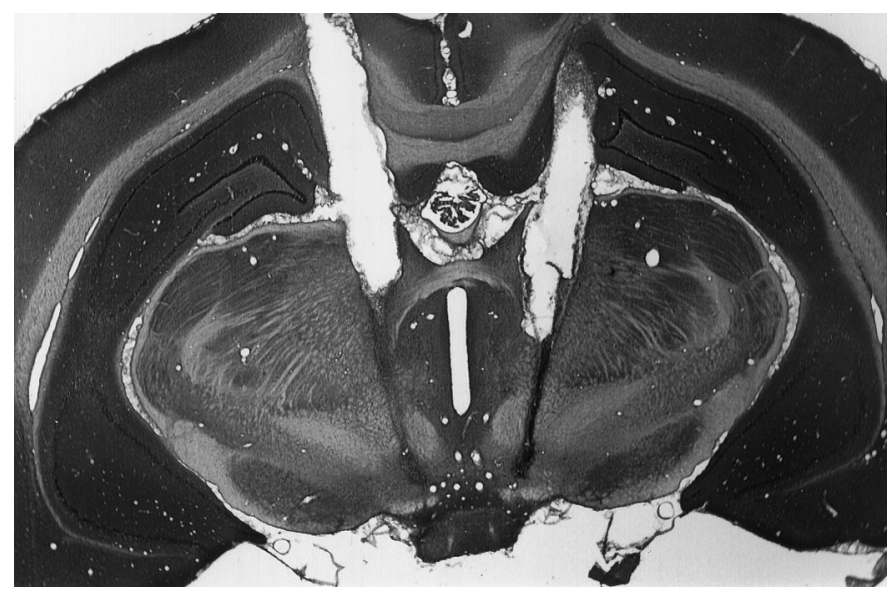

Figure 1. A photomicrograph of a Nissl-stained coronal section showing representative cannulae placements into the VTA.

$\alpha$-flupentixol $(n=7)$ or saline $(n=7)$. After a 1 week recovery period, all animals were tested as described above.

Effects of TPP lesions on intra-VTA morphine-mediated place preferences. A total of four groups, two sham and two TPP-lesioned, were used for this experiment. One group of sham $(n=9)$ and one group of TPP-lesioned $(n=8)$ animals were conditioned while previously drug-naive. The remaining two groups, one sham $(n=8)$ and one TPP-lesioned $(n=7)$, were made opiate-dependent and trained while in a state of opiate withdrawal. In all cases, animals were conditioned with $500 \mathrm{ng}$ per $0.5 \mu \mathrm{l}$ per side intra VTA morphine dose. Once testing was completed, sham and TPP-lesioned animals that were conditioned opiate-dependent and in a state of withdrawal were given an additional week to recover from dependence. To verify behaviorally the effectiveness of the TPP lesions, the previously opiate-dependent animals were counterbalanced with respect to the drug-paired environment within groups and subsequently conditioned using a systemic $10 \mathrm{mg} / \mathrm{kg}$ (i.p.) dose of morphine (the animals conditioned with intra-VTA morphine while drug-naive were not retrained). That is, half the animals in each of the TPP and sham previously dependent groups were slotted to receive morphine pairings to the same side as the first time they were trained, whereas the other half of the animals in each group were slotted to receive morphine pairings to the side that animals had previously received intra-VTA saline. Previous evidence shows that once animals have recovered from dependence, the rewarding properties of $10 \mathrm{mg} / \mathrm{kg}$ (i.p.) morphine are TPP-dependent (Nader et al., 1994). Thus, effective lesions of the TPP should block the acquisition of place preferences for this dose of morphine.

\section{RESULTS}

\section{Histology and preliminary investigations}

All animals that were included in the behavioral analysis had appropriate injector cannulae placements either within the VTA (Fig. 1) or dorsal to the VTA for the dorsal control groups. As with all central cannulae experiments, some cell death was noted around the tip of the injector. Animals conditioned with the 500 ng per $0.5 \mu \mathrm{l}$ per side dose (mean time spent in the saline paired environment at testing was $206.9 \pm 11 \mathrm{sec}$ and in the morphinepaired environment was $270.8 \pm 19 \mathrm{sec} ; t=2.6, p<0.05)$ or 2500 ng per $0.5 \mu \mathrm{l}$ per side dose (mean time spent in the saline-paired environment at testing was $173.7 \pm 30 \mathrm{sec}$ and in the morphinepaired environment was $340.9 \pm 38 \mathrm{sec} ;=2.5, p<0.05$ ), but not the $250 \mathrm{ng}$ per $0.5 \mu \mathrm{l}$ per side dose (mean time spent in the saline-paired environment at testing was $253.2 \pm 54 \mathrm{sec}$ and in the morphine-paired environment was $276.1 \pm 52 \mathrm{sec} ; t=0.2, p>$ $0.05)$, showed significant place preferences for the morphine versus the saline paired environment. Therefore, the dose of $500 \mathrm{ng}$ per $0.5 \mu \mathrm{l}$ per side intra-VTA morphine was chosen as the training dose of morphine for the remaining studies.
Animals trained previously drug-naive or while in a state of opiate dependence and withdrawal did not demonstrate significant preferences for environments paired with $500 \mathrm{ng}$ per $0.5 \mu \mathrm{l}$ per side morphine-injected $1 \mathrm{~mm}$ dorsal to the VTA (for the naive group, mean time spent in the saline paired environment at testing was $215.1 \pm 29 \mathrm{sec}$ and in the morphine-paired environment was $256.7 \pm 23 \mathrm{sec} ; t=0.86, p>0.05$; for animals trained in withdrawal, the mean time spent in the saline-paired environment at testing was $232 \pm 16 \mathrm{sec}$ and in the morphine-paired environment was $213.5 \pm 26 \mathrm{sec} ; t=0.5, p>0.05)$. These results demonstrate that the place preferences acquired with morphine microinjections into the VTA are not the product of the drug diffusion up the cannulae tract with action at a distant dorsal site. Furthermore, the mechanisms supporting morphine's rewarding properties within the VTA are opiate receptor-mediated. Previously drug-naive animals did not spend significantly more time in environments paired with microinjections of $500 \mathrm{ng}$ per $0.5 \mu \mathrm{l}$ per side of the inactive (+)-morphine isomer (Jacquet et al., 1977) into the VTA than in environments paired with intra-VTA saline injections (the mean time spent in the saline-paired environment at testing was $214.4 \pm 39 \mathrm{sec}$ and in the morphine-paired environment was $216.3 \pm 34 \mathrm{sec} ; t=0.03, p>0.05$ ). Together, these results demonstrate that our microinjected, just suprathreshold dose of morphine must be acting via a stereospecific opiate receptor-mediated mechanism within the VTA itself to produce its rewarding properties.

\section{Effects of $\alpha$-flupentixol on intra-VTA morphine- mediated place preferences}

Pretreatment with a high dose of $\alpha$-flupentixol $(0.8 \mathrm{mg} / \mathrm{kg}$, i.p. $)$ $2.5 \mathrm{hr}$ before each conditioning session had no effect on the acquisition of conditioned place preferences for environments paired with a low dose of intra-VTA morphine (500 ng per 0.5 $\mu l$ per side) in previously drug-naive animals (Fig. $2 A$ ), but completely blocked the acquisition of these same conditioned place preferences in rats trained while opiate-dependent and in withdrawal (Fig. 2B). An ANOVA that compared the effects of pretreatment ( $\alpha$-flupentixol vs saline) with times spent in the morphine versus saline paired environments revealed no significant interaction between these two variables for animals trained previously drug-naive $\left(F_{(1,12)}=0.9, p>0.05\right)$. There was, however, a significant main effect of time $\left(F_{(1,12)}=11.9\right.$, $p<0.05)$, revealing the significant place preferences shown by both previously drug-naive groups. Conversely, a similar analysis on the scores of animals trained while in a state of opiate withdrawal revealed a significant interaction between pretreatment and times spent in the morphine- versus saline-paired environments $\left(F_{(1,15)}=9.5, p<0.05\right)$. These results suggest that $\alpha$-flupentixol only blocked morphine's rewarding properties in animals that were trained while in a state of opiate dependence and withdrawal.

Animals conditioned initially while previously drug-naive and then again later while opiate-dependent and deprived showed the same pattern of results (Fig. 3). $\alpha$-Flupentixol pretreatment had no effect on the initial acquisition of conditioned place preferences for environments paired with $500 \mathrm{ng}$ per $0.5 \mu \mathrm{l}$ per side morphine into the VTA in previously drug-naive animals (Fig. $3 A$ ). An ANOVA comparing the effects of pretreatment ( $\alpha$-flupentixol vs saline) with times spent in the separate test environments (morphine- vs salinepaired) showed that there was no significant interaction between these two variables $\left(F_{(1,12)}=0, p>0.05\right)$. However, 
A

\section{Previously Drug Naive}

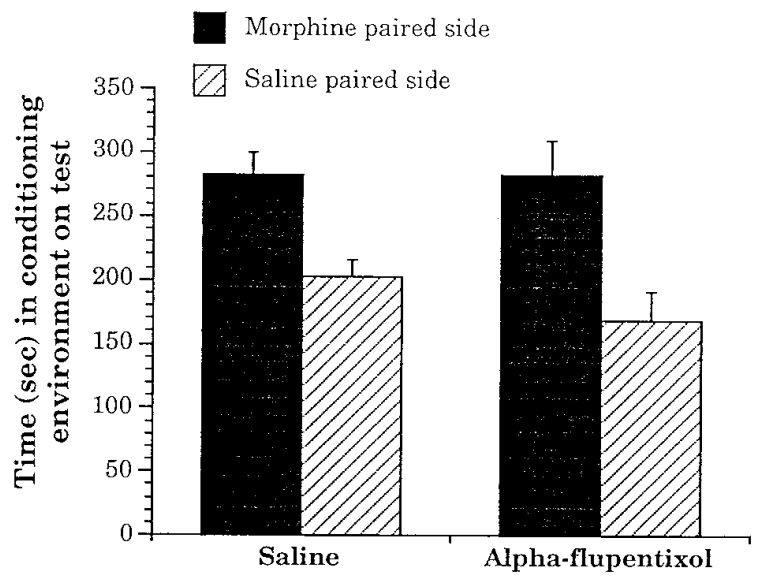

B

\section{Opiate Dependent and Withdrawn}

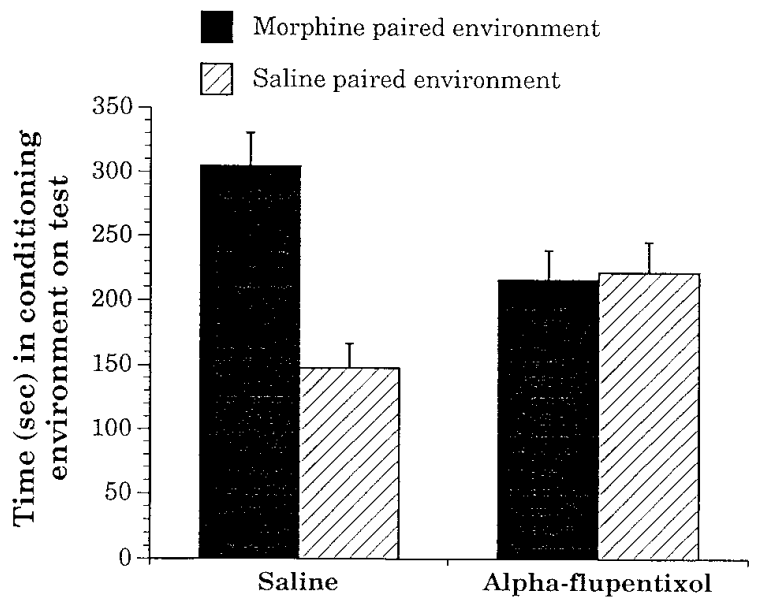

Figure 2. The effects of saline or $\alpha$-flupentixol pretreatment on the absolute times spent in environments paired with intra-VTA injections of either $500 \mathrm{ng}$ per $0.5 \mu \mathrm{l}$ per side morphine or $0.5 \mu \mathrm{l}$ per side saline in separate groups of animals that were trained $(A)$ previously drug-naive or $(B)$ in a state of opiate dependence and withdrawal. Data are represented as mean \pm SEM.

there was a significant main effect of time, $\left(F_{(1,12)}=13.6, p<\right.$ $0.05)$. When these same animals were subsequently retrained while in a state of dependence and withdrawal, $\alpha$-flupentixol blocked the normal preferences for environments paired with $500 \mathrm{ng}$ per $0.5 \mu \mathrm{l}$ per side morphine into the VTA (Fig. $3 B$ ). An ANOVA revealed a significant interaction between the times spent in the test environments (morphine- vs saline-paired) with pretreatment ( $\alpha$-flupentixol vs saline) $\left(F_{(1,12)}=6.1, p<\right.$ $0.05)$. Furthermore, there were no interactions between either the environment to which morphine was paired or the pretreatment animals received the first time they were conditioned and the times spent in morphine- versus saline-paired environments on the second conditioning test $\left(F_{(1,12)}=2.5, p>0.05\right.$ and $F_{(1,12)}=0.0, p>0.05$, respectively). Thus, even within the same animals, pretreatment with a broad-spectrum dopamine antagonist only blocked morphine's rewarding properties in

\section{Previously Drug Naive}

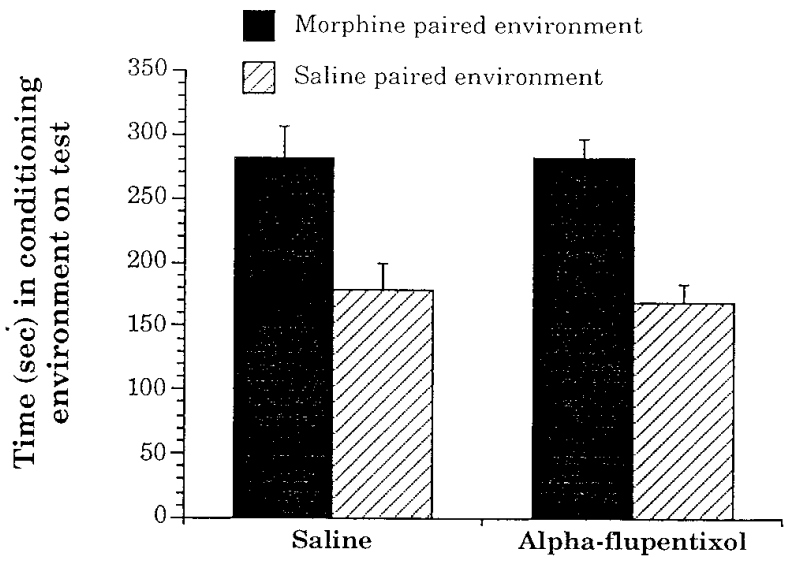

B Opiate Dependent and Withdrawn

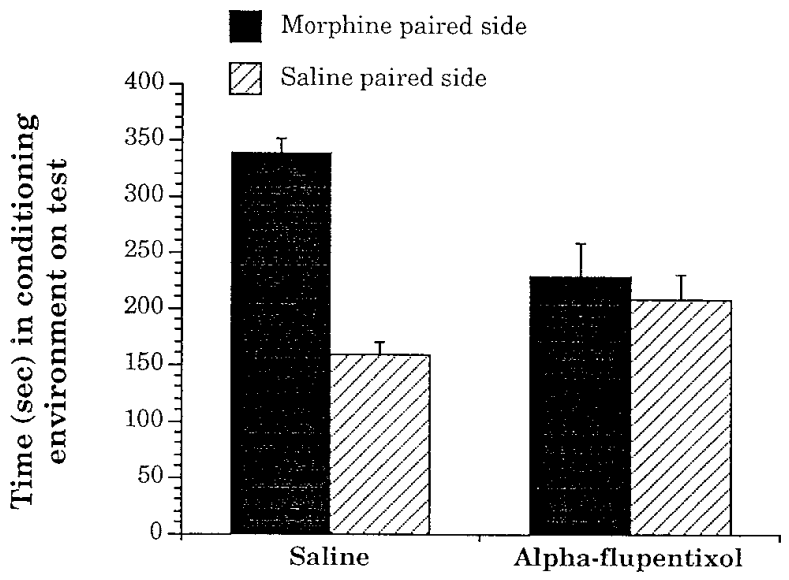

Figure 3. The effects of saline or $\alpha$-flupentixol pretreatment on the absolute times spent in environments paired with intra-VTA injections of either $500 \mathrm{ng}$ per $0.5 \mu \mathrm{l}$ per side morphine or $0.5 \mu \mathrm{l}$ per side saline in animals that were initially trained previously drug-naive $(A)$ and then subsequently retrained while in a state of opiate dependence and withdrawal $(B)$. Data are represented as mean \pm SEM.

animals that were in an opiate-dependent and withdrawn state, but not when they were drug-naive.

\section{Effects of TPP lesions on intra-VTA morphine- mediated place preferences}

All animals included in the behavioral analyses of this experiment had the majority of the ventromedial TPP bilaterally lesioned (Figs. 4, 5). Histological analyses revealed that $\sim 50 \%$ of the ibotenic acid-lesioned rats had lesions with necrotic, vacuolated centers. Such a phenotype may be the result of the long interval between surgery and histology (Brown and Fibiger, 1993), which in the present case was $\sim 3$ months. Lesions of the TPP blocked the acquisition of intra-VTA morphine place preferences in previously drug-naive, but not opiate-dependent and withdrawn, animals (Fig. 6). For animals trained previously drug-naive, there was a significant interaction of surgery (sham- vs TPP-lesioned) with times spent in the morphine versus saline paired environments $\left(F_{(1,15)}=8.8, p<0.05\right.$; Fig. $\left.5 A\right)$. A similar analysis on the 

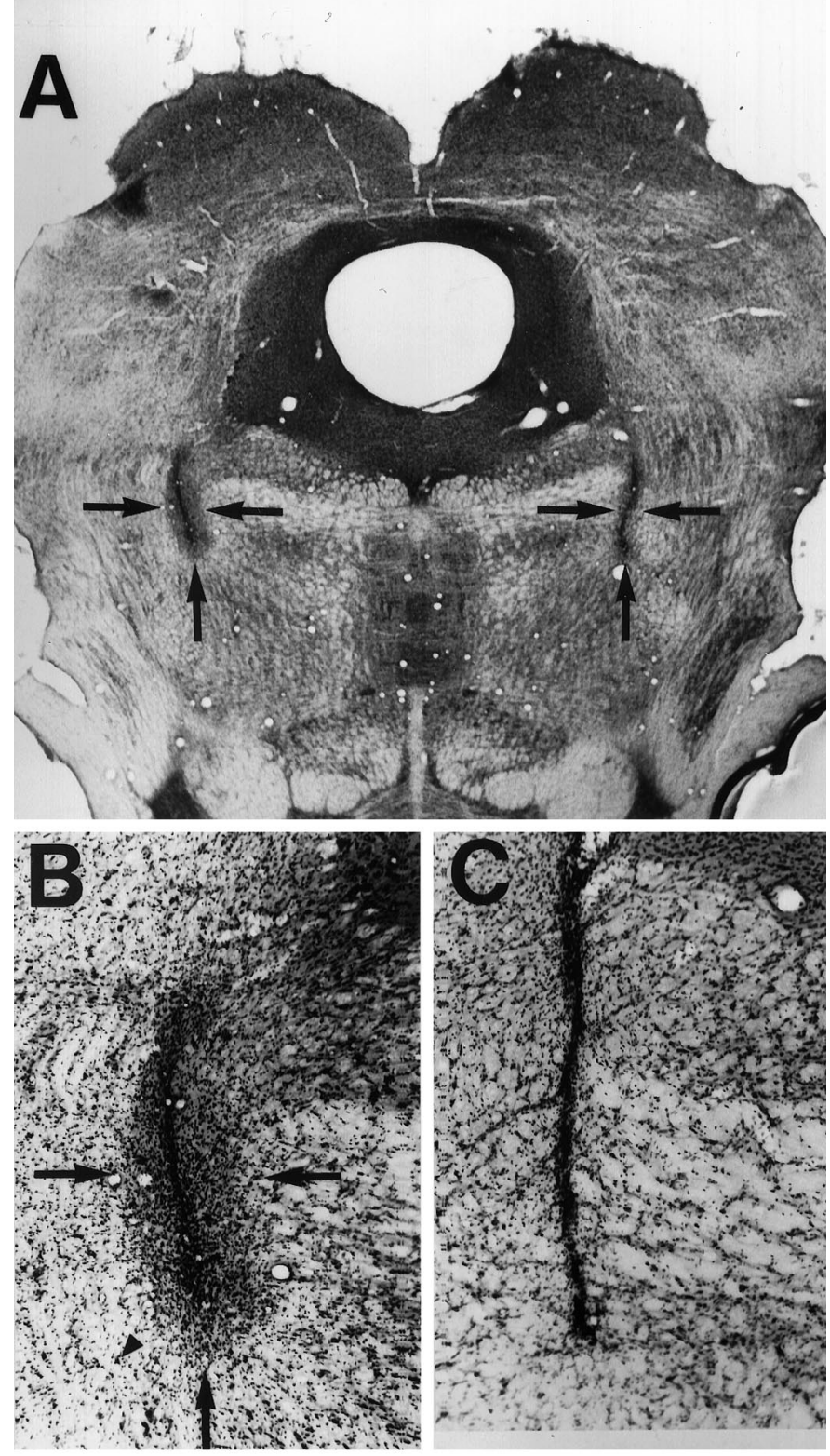

Figure 4. A, Photomicrograph of a Nissl-stained coronal section showing the extent (arrows) of a representative bilateral ibotenic acid induced lesion of the TPP. $B$, Higher-magnification photomicrograph of the left side of the ibotenic acid-induced lesion shown in $A$. The extent of the lesion is indicated by arrows, whereas a healthy neuron is indicated by an arrowhead. $C$, High-magnification photomicrograph of the left side of a sham lesion.

scores of animals trained while in a state of opiate withdrawal showed that there was no interaction between these two variables $\left(F_{(1,13)}=0.1, p>0.05\right.$; Fig. $\left.5 B\right)$. There was, however, a significant main effect of times spent in the morphine- versus saline-paired environments $\left(F_{(1,13)}=6.4, p<0.05\right)$, demonstrating that both withdrawal groups showed significant conditioned morphine place preferences. Given that some of the TPP-lesioned rats had necrotic lesions, we also compared the scores of TPP-lesioned rats with and without necrotic lesions. There were no significant interactions between lesion type (necrotic vs non-necrotic) with times spent in the morphine- versus saline-paired environments for animals trained either previously drug-naive $\left(F_{(1,6)}=0.34, p>\right.$

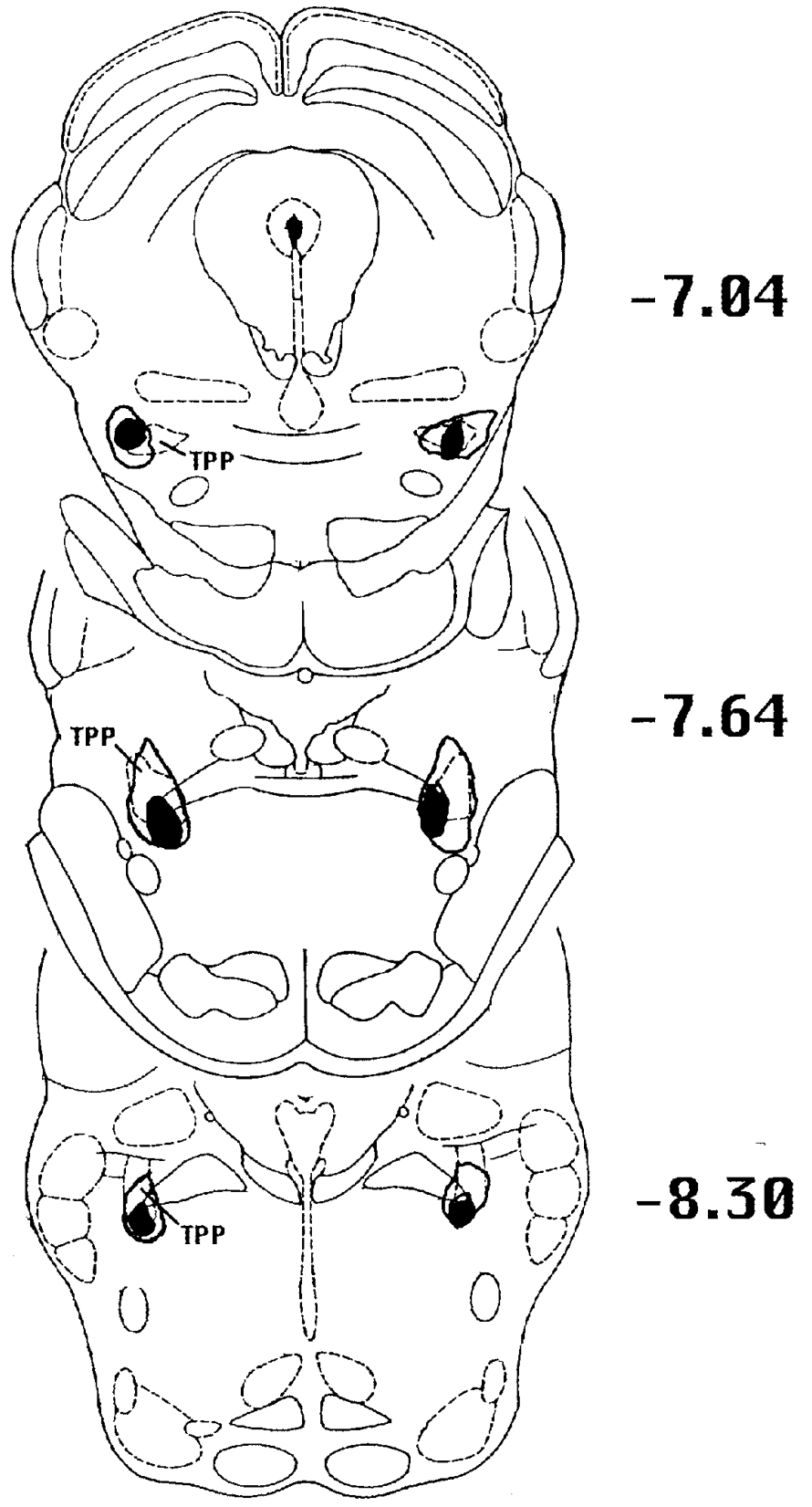

Figure 5. A schematic representation of the size and extent of the ibotenic acid lesions of the ventromedial TPP. The filled-in areas represent the volume of the smallest lesion. The open outlined areas represent the volume of the largest lesion. The numbers to the right indicate the distance caudal from Bregma in millimeters.

$0.05)$ or in a state of opiate dependence and withdrawal $\left(F_{(1,5)}=\right.$ $0.05, p>0.05)$. Thus, any damage to fibers of passage did not produce any additional behavioral deficit. These results suggest that lesions of the TPP blocked intra-VTA morphine's rewarding properties in previously drug-naive, but not in opiate-dependent and withdrawn, rats.

The sham- and TPP-lesioned animals that were trained in a state of opiate withdrawal were allowed to recover from dependence and were retrained with a $10 \mathrm{mg} / \mathrm{kg}$ systemic dose of morphine. Two rats were removed from this final portion of the study because of sickness. TPP-lesioned rats that had acquired previously conditioned place preferences for environments 
A

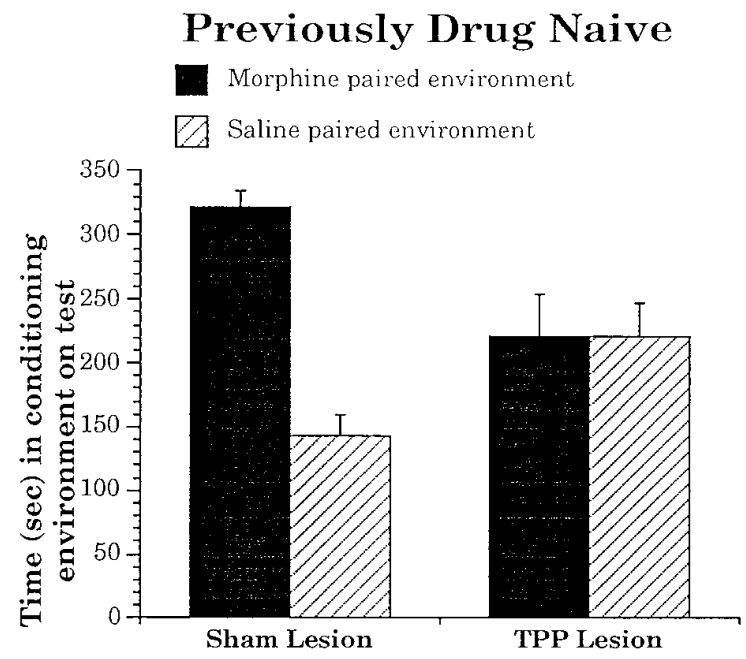

B

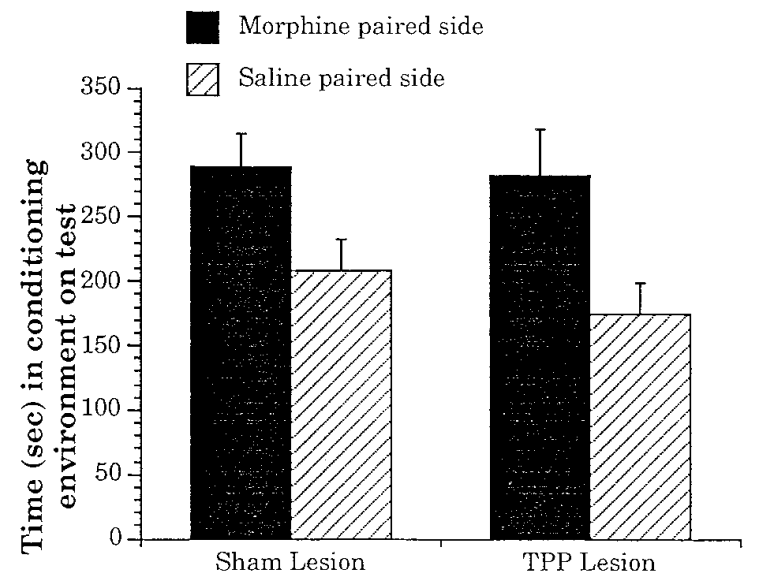

Figure 6. The effects of bilateral sham or ibotenic acid lesions of the TPP on the absolute times spent in environments paired with intra-VTA injections of either $500 \mathrm{ng}$ per $0.5 \mu \mathrm{l}$ per side morphine or $0.5 \mu \mathrm{l}$ per side saline in separate groups of animals that were trained $(A)$ previously drug-naive or $(B)$ in a state of opiate dependence and withdrawal. Data are represented as mean \pm SEM.

paired with intra-VTA morphine while in opiate withdrawal did not acquire conditioned place preferences for environments paired with systemic morphine after recovering from dependence. An ANOVA on the scores of the remaining rats comparing the effects of lesions (TPP or sham) with times (morphine- vs saline-paired environment) revealed a significant interaction between these two variables $\left(F_{(1,11)}=5.3, p<\right.$ $0.05)$. For the sham-lesioned group, the mean time spent in the saline-paired environment at testing was $166 \pm 19.6 \mathrm{sec}$ and in the morphine-paired environment was $305 \pm 27.3 \mathrm{sec}$. For the TPP-lesioned group, the mean time spent in the saline-paired environment at testing was $235 \pm 24.4 \mathrm{sec}$ and in the morphinepaired environment was $215 \pm 24.2 \mathrm{sec}$. Thus, in the same animals that were trained initially in a state of opiate withdrawal and then subsequently retrained after having recovered from dependence, lesions of the TPP only blocked opiate reward when animals are in nonwithdrawal states.

\section{DISCUSSION}

Lesions of the TPP and $\alpha$-flupentixol pretreatment doubledissociate two independent motivational substrates within the VTA itself. TPP lesions, but not $\alpha$-flupentixol pretreatment, blocked the rewarding effects both of intra-VTA morphine in animals that were conditioned previously drug-naive and of systemic morphine in animals that had recovered from dependence. Conversely, when animals were conditioned in a state of opiate dependence and withdrawal, the opposite pattern of results was found. $\alpha$-Flupentixol pretreatment, but not TPP lesions, blocked the rewarding properties that resulted from morphine microinjections into the VTA. Furthermore, even in single animals that were initially conditioned previously drug-naive and then retrained while in a state of opiate withdrawal, $\alpha$-flupentixol's rewardblocking effects were constrained to when animals were in withdrawal. Thus, by manipulating only the state in which animals are conditioned but leaving constant the training dose, conditioning protocol, pretreatment, and variation in cannulae placement (by using the same animals, first trained in one state, then counterbalanced and subsequently retrained in the opposite state), we have demonstrated that two separate neural systems in the VTA can be engaged in predictable ways to mediate the motivational properties of morphine. Training animals while in a state of opiate dependence and withdrawal (deprivation) will cause morphine's rewarding properties to be dopamine-mediated. On the other hand, training animals while in non-opiate-withdrawal states (nondeprivation) causes morphine's rewarding properties to be TPP-dependent.

The behavioral deficits of $\alpha$-flupentixol pretreatment in opiatedependent and withdrawn rats and of TPP lesions in previously drug-naive animals are not attributable to nonspecific sensory, motor, or learning deficits. $\alpha$-Flupentixol pretreatment in previously naive rats or TPP lesions in opiate-dependent and withdrawn rats had no effects on the normal acquisition of conditioned place preferences, demonstrating that these manipulations did not prevent animals from perceiving the environment and learning an association between the environment and morphine's rewarding properties.

The most obvious candidate pathway mediating the dopaminedependent system is the mesolimbic pathway. Indeed, recent unpublished results from our laboratory suggest that the acquisition of conditioned place preferences in opiate-dependent and withdrawn rats can be antagonized by $\alpha$-flupentixol microinjections into the nucleus accumbens. Although the pathway mediating morphine reward in naive animals is not known, the most direct route is for morphine to act on opiate receptors on nondopaminergic VTA neurons (Johnson and North, 1992) that descend to the TPP (Semba and Fibiger, 1992; Steininger et al., 1992). This view is in contrast to the current focus on ascending catecholamine systems as the basis of reward (Koob, 1992; Wise, 1996).

An alternate interpretation of the present data is that the reported dissociation is quantitative, not qualitative, in nature. This interpretation posits a process of sensitization as being the critical variable underlying our dissociation. In this case, TPP lesions that are normally sufficient to block morphine's rewarding properties in opiate-naive animals are ineffective in opiatedependent and withdrawn rats because the pathway mediating morphine reward has been sensitized by chronic opiate administration. To antagonize this enhanced reward, interference of dopamine transmission is required. However, this interpretation is untenable for two reasons. First, interference with dopamine 
transmission that is sufficient to block the sensitized opiate reward present in dependent and withdrawn animals should have been sufficient to block the weaker opiate reward in previously drugnaive animals. The inability of the dopamine antagonist to block opiate reward in previously drug-naive rats suggests the dissociation is qualitative, not quantitative, in nature. Second, sensitization is a long-lasting process (Kalivas and Stewart, 1991; Robinson and Berridge, 1993). Indeed, studies have reported that the mesolimbic pathway remains hyper-responsive to morphine a month after the termination of initial opiate administration (Spanagel et al., 1993). This interpretation predicts that once the mesolimbic pathway has been sensitized, then morphine reward should continue to be dopamine-mediated regardless of whether rats are in a state of deprivation. Our results showing that TPP lesions blocked the acquisition of conditioned place preferences for environments paired with systemic morphine in rats that had recovered from dependence contradict this prediction. Furthermore, the behavioral effects of TPP lesions appear to be independent of reward magnitude because lesions of the TPP block the rewarding properties of systemic morphine over the entire dose range usable in drug-naive animals, but have no effect on the rewarding properties of a low, $2 \mathrm{mg} / \mathrm{kg}$ dose of morphine in opiate-dependent and withdrawn rats (Bechara and van der Kooy, 1989, 1992a,b). Thus, we suggest that the critical qualitative difference in the processes being mediated by these two systems is the production of reward in the absence or presence of opiate dependence and withdrawal.

According to our model, dopamine should not play any role in mediating the rewarding properties of opiates in drug-naive animals. However, there are a number of previously reported findings with both heroin (Bozarth and Wise, 1981; Spyraki et al., 1983; Hand et al., 1989) and morphine (Phillips et al., 1983; Leone and Di Chiara, 1987; Shippenberg and Herz, 1988; Acquas and Di Chiara, 1994) that contradict this hypothesis. Although the majority of these studies can be questioned on procedural grounds (see Nader et al., 1994), one study that used an unbiased place conditioning paradigm has reported that unilateral intraaccumbens injections of SCH 23390, at a dose that has no unconditioned motivational effects itself, blocked the acquisition of low-dose systemic morphine place preferences in drug-naive animals (Shippenberg et al., 1993). Based on this finding, it could be argued that morphine's rewarding properties are D1-mediated and, therefore, that SCH 23390 (a specific D1 antagonist) is more effective than $\alpha$-flupentixol (a broad-spectrum antagonist) in blocking morphine's motivational properties. This interpretation is unlikely, however, given that $\alpha$-flupentixol is more effective than SCH 23390 at inhibiting dopamine-stimulated adenylate cyclase activity (a measure of D1 receptor activity) (Hyttel, 1978, 1984). Furthermore, it is difficult to reconcile the unilateral intraaccumbens SCH 23390 blockade of conditioned place preferences for environments paired with systemic morphine with the recent findings that lesions of the entire ventral striatum do not block the acquisition of conditioned place preferences for morphine-paired environments (Olmstead and Franklin, 1996).

A neurobiological distinction between nondeprived and deprived states may clarify some of the conflicting results obtained with heroin self-administration. The nondeprived/deprived model predicts that the acquisition of opiate self-administration (when animals have had minimal drug exposure) will be blocked by lesions of the TPP but will be insensitive to dopamine antagonist pretreatment. Consistent with these predictions are the findings that lesions of the TPP (Olmstead et al., 1993), but neither dopamine antagonist pretreatment nor 6-OHDA lesions of the nucleus accumbens (van Ree and Ramsey, 1987; Gerrits et al., 1994; Gerrits and van Ree, 1996), blocked the acquisition of heroin self-administration.

Previous findings have shown that the amount of heroin selfadministered in order to attain a stable baseline of responding is sufficient to induce states of dependence (Nader et al., 1994). Thus, the nondeprived/deprived model predicts that once animals have acquired a stable baseline of operant responding, then dopamine antagonist pretreatment, but not TPP lesions, will block operant responding for heroin. Indeed, TPP lesions have no effect on the rate of heroin self-administration in animals that previously had acquired a stable baseline (Nader et al., 1994). The findings with dopaminergic manipulations on the maintenance of heroin self-administration are more controversial. Under conditions in which animals have acquired a stable baseline rate of responding for heroin, evidence from different studies suggests that the reinforcing effects of heroin are affected by dopaminergic manipulations (presumably because of opiate actions in the VTA) (Britt and Wise, 1983; Nakajima and Wise, 1987) or are not affected by dopaminergic manipulations (possibly because of actions in the nucleus accumbens) (Ettenberg et al., 1982; Pettit et al., 1984). We can imagine three reasons why 6-OHDA lesions of the nucleus accumbens may not block the maintenance of heroin selfadministration (Pettit et al., 1984). First, it is possible that when the dopaminergic systems are challenged, opiates can sometimes still act on receptors located efferent to dopaminergic neurons in the deprived motivational system. Second, it is possible that the lesions did not decrease dopamine levels sufficiently. Third, 6-OHDA lesions may have blocked the primary motivational properties of heroin, but the amount of heroin self-administered due to conditioned responding alone was sufficient to take animals from the deprived state to the nondeprived state. Once in nondeprived states, 6-OHDA lesions of the nucleus accumbens should not affect self-administration behavior because heroin's rewarding properties are no longer dopamine-dependent.

In conclusion, we have demonstrated that two independent motivational systems exist within the VTA itself, the differential activation of which is predicated on whether animals are in states of withdrawal (deprivation) or not (nondeprivation). A dopamineindependent mechanism mediates the rewarding properties of morphine only when animals are in nondeprived opiate states and is dependent on the TPP nucleus. In animals that are in opiatedeprived states, a dopaminergic system is engaged to mediate morphine reward. Furthermore, the psychological boundary between nondeprived and deprived states identified with intra-VTA morphine in the present study is consistent with a similar boundary between nondeprivation and deprivation states using neurobiologically manipulations of the reward produced by food, systemic morphine, and systemic heroin (Bechara and van der Kooy, 1992a; Bechara et al., 1992; Nader et al., 1994; Nader and van der Kooy, 1996).

\section{REFERENCES}

Acquas E, Di Chiara G (1994) D1 receptor blockade stereospecifically impairs the acquisition of drug-conditioned place preference and placeaversion. Behav Pharmacol 5:555-569.

Bechara A, van der Kooy D (1989) The tegmental pedunculopontine nucleus: a brain-stem output of the limbic system critical for the conditioned place preferences produced by morphine and amphetamine. J Neurosci 9:3400-3409.

Bechara A, van der Kooy D (1992a) A single brain substrate mediates the motivational effects of both opiates and food in non-deprived, but not in deprived animals. Behav Neurosci 106:351-363. 
Bechara A, van der Kooy D (1992b) Chronic exposure to morphine does not alter the neural tissue subserving its acute rewarding properties: apparent tolerance is overshadowing. Behav Neurosci 106:364-374.

Bechara A, Harrington F, Nader K, van der Kooy D (1992) Neurobiology of motivation: double dissociation of two motivational mechanisms mediating opiate reward in drug-naive versus drug-dependent animals. Behav Neurosci 106:798-807.

Bechara A, Nader K, van der Kooy D (1995) Neurobiology of withdrawal motivation: evidence for two separate aversive effects produced in morphine-naive versus morphine-dependent rats by both naloxone and spontaneous withdrawal. Behav Neurosci 109:91-105.

Bozarth MA, Wise RA (1981) Heroin reward is dependent on a dopaminergic substrate. Life Sci 29:1881-1886.

Britt MD, Wise RA (1983) Ventral tegmental site of opiate reward: antagonism by a hydrophilic opiate receptor blocker. Brain Res 258:105-108.

Brown EE, Fibiger HC (1993) Differential effects of excitotoxic lesions of the amygdala on cocaine-induced conditioned locomotion and conditioned place preference. Psychopharmacology 113:123-130.

Creese I, Burt DR, Snyder SH (1976) Dopamine binding predicts clinical and pharmacological potencies of antischizophrenic drugs. Science 192:481-483.

Ettenberg A, Pettit HO, Bloom FE, Koob GF (1982) Heroin and cocaine intravenous self-administration in rats: mediation by separate neural systems. Psychopharmacology 78:204-209.

Gerrits MAFM, van Ree JM (1996) Effect of nucleus accumbens dopamine depletion on motivational aspects involved in initiation of cocaine and heroin self-administration in rats. Brain Res 713:114-124.

Gerrits M, Ramsey NF, Wolternink G, van Ree JM (1994) Lack of evidence for an involvement of the nucleus accumbens dopamine $D_{1}$ receptors in the initiation of heroin self-administration in the rat. Psychopharmacology 114:486-494.

Hand TH, Stinus L, Le Moal M (1989) Differential mechanisms in the acquisition and expression of heroin-induced place preference. Psychopharmacology 98:61-67.

Harrington F, van der Kooy D (1992) Deprivation state determines the motivational effects of neuroleptics in rats. Psychobiology 20:294-299.

Hubner CB, Koob GF (1990) The ventral pallidum plays a role in mediating cocaine and heroin self-administration in the rat. Brain Res 508:20-29.

Hyttel J (1978) A comparison of the effect of neuroleptic drugs on the binding of ${ }^{3} \mathrm{H}$-halperidol and ${ }^{3} \mathrm{H}$-cis-(Z)-flupentixol and on adenylate cyclase activity. Prog Neuropsychopharmacol 2:329-335.

Hyttel J (1984) Functional evidence for selective dopamine D-1 receptor blockade by SCH 23390. Neuropharmacology 23:1395-1401.

Jacquet YF, Klee WA, Rice KC (1977) Stereospecific and nonstereospecific effects of $(+)$ - and (-)-morphine: evidence for a new class of receptors? Science 198:842-845.

Jaeger TV, van der Kooy D (1993) Morphine acts in the parabrachial nucleus, a pontine viscerosensory relay, to produce discriminative effects. Psychopharmacology 110:76-84.

Johnson SW, North RA (1992) Opioids excite dopamine neurons by hyperpolarization of local interneurons. J Neurosci 12:483-488.

Kalivas PW, Stewart J (1991) Dopamine transmission in the initiation and expression of drug- and stress-induced sensitization of motor activity. Brain Res Rev 16:223-244.

Koob GF (1992) Drugs of abuse: anatomy, pharmacology and function of reward pathways. Trends Pharmacol Sci 13:177-184.

Koob GF, Bloom FE (1988) Cellular and molecular mechanisms of drug dependence. Science 242:715-723.
Leone P, Di Chiara G (1987) Blockade of D1 receptors by SCH 23390 antagonizes morphine and amphetamine induced place preference conditioning. Eur J Pharmacol 135:251-254.

Nader K, van der Kooy D (1994) The motivation produced by morphine and food is isomorphic: approaches to specific motivational stimuli are learned. Psychobiology 22:68-76.

Nader K, van der Kooy D (1996) Clonidine antagonizes the aversive effects of opiate withdrawal and the rewarding effects of morphine only in opiate withdrawn rats. Behav Neurosci 110:389-400.

Nader K, Harrington F, Bechara A, van der Kooy D (1994) Neuroleptics block high but not low dose heroin place preferences: further evidence for a two system model of motivation. Behav Neurosci 108:1128-1138.

Nakajima S, Wise RA (1987) Heroin self-administration in the rat suppressed by SCH 23390. Soc Neurosci Abstr 13:1545.

Olmstead MC, Franklin KBJ (1996) Differential effects of ventral striatal lesions on the conditioned place preference induced by morphine or amphetamine. Neuroscience 71:701-708.

Olmstead MC, Munn EM, Wise RA (1993) Effects of pedunculopontine nucleus (PPN) lesions on the acquisition of iv heroin selfadministration. Soc Neurosci Abstr 19:1023.

Pettit HO, Ettenberg A, Bloom FE, Koob GF (1984) Destruction of dopamine in the nucleus accumbens selectively attenuates cocaine but not heroin self-administration in rats. Psychopharmacology 84:167-173.

Phillips AG, LePiane FG, Fibiger H (1983) Dopaminergic mediation of reward produced by direct injection of enkephalin into the ventral tegmental area of the rat. Life Sci 33:2505-2511.

Robinson TE, Berridge KC (1993) The neural basis of drug craving: an incentive-sensitization theory of addiction. Brain Res Rev 18:247-291.

Semba K, Fibiger HC (1992) Afferent connections of the laterodorsal and pedunculopontine tegmental nuclei in the rat: a retro- and anterograde transport and immunohistochemical study. J Comp Neurol 323:387-410.

Shippenberg TS, Herz A (1988) Motivational effects of opioids: influence of D1 versus D2 receptor antagonists. Eur J Pharmacol 151:233-242.

Shippenberg TS, Bals-Kubik R, Herz A (1993) Examination of the neurochemical substrates mediating the motivational effects of opioids: role of the mesolimbic dopamine system and D1 vs D2 dopamine receptors. J Pharmacol Exp Ther 265:53-59.

Spanagel R, Almeida OFX, Shippenberg TS (1993) Long lasting changes in morphine-induced mesolimbic dopamine release after chronic morphine exposure. Synapse 14:243-245.

Spyraki C, Fibiger HC, Phillips AG (1983) Attenuation of heroin reward in rats by disruption of the mesolimbic dopamine system. Psychopharmacology 79:278-283.

Steininger TL, Rye DB, Wainer BH (1992) Afferent projections to the cholinergic pedunculopontine tegmental nucleus and adjacent midbrain extrapyramidal area in the albino rat. I. Retrograde tracing studies. J Comp Neurol 321:515-543.

van Ree JM, Ramsey NF (1987) The dopamine hypothesis of opiate reward challenged. Eur J Pharmacol 134:239-243.

Wise RA (1988) The neurobiology of craving: implications for understanding and treatment of addiction. J Abnormal Psychol 97:118-132.

Wise RA (1996) Addictive drugs and brain stimulation reward. Annu Rev Neurosci 19:319-340.

Wise RA, Bozarth MA (1987) A psychostimulant theory of addiction. Psychol Rev 94:1-24.

Wise RA, Rompre PP (1989) Brain dopamine and reward. Annu Rev Psychol 40:191-225. 